\title{
Sternal Muscle: A Case Report
}

\author{
Pamela Kelly Farias de Aguiar ${ }^{1} \quad$ Anna Caroline Duarte Costa Silva ${ }^{2}$ André de Sá Braga Oliveira ${ }^{1}$ \\ Luciano Edgley dos Santos ${ }^{2}$ Felippe Barbosa Gomes ${ }^{1}$ Thiago de Oliveira Assis ${ }^{1,2,3}$
}

\footnotetext{
${ }^{1}$ Department of Morphology, Universidade Federal da Paraíba, João Pessoa, PB, Brazil

2 Department of Medicine and Nutrition, Unifacisa, Campina Grande, $\mathrm{PB}$, Brazil

${ }^{3}$ Department of Biology, Universidade Federal da Paraíba, Campina Grande, PB, Brazil
}

J Morphol Sci 2019;36:141-144.

\author{
Address for correspondence Thiago de Oliveira Assis, PhD, \\ Departamento de Morfologia, Universidade Federal da Paraíba, \\ Cidade Universitária, S/N, Castelo Branco III - João Pessoa, PB, Brazil, \\ CEP: 58051-900. (e-mail: thiago.oa@hotmail.com).
}

\begin{abstract}
Keywords

- sternal muscle

- anatomical variation

- clinical anatomy

Introduction The sternal muscle is an anatomical variation found in the anterior region of the thorax.

Objective To report the anatomical characteristics of a new type of sternal muscle. Case Report This was a dissection study in which the sternal muscle found was unilateral and long.

Discussion Proximal fixation differs from the classification adopted for these cases. Documentation of sternal muscle variations can improve the theoretical database in anatomy as well as aid diagnoses, reducing the probability of the unexpected during clinical and/or surgical thorax-related investigations.
\end{abstract}

\section{Introduction}

The sternal muscle, which is not present in the American population and is more present in the northern China population, presents as an anatomical variation superficially situated at the pectoralis major muscle, usually unilateral, without epidemiological variation in relation to sexual dimorphism. ${ }^{1}$ Its low occurrence, estimated to be $\sim 8 \%$, and the possibility of confounding it with tumors in the sternal region, justifies its descriptions upon identification. The objective of the present article is to report a case of sternal muscle in a human cadaver.

\section{Case Report}

This is an observational dissection study. In the dissection routine at the Anatomy Laboratory of the Morphology Department of the Universidade Federal da Paraíba (Campus I), João Pessoa, state of Paraíba, Brazil, the sternal muscle was found, dissected by routine technique and anatomically characterized.

The most commonly used classification for sternal muscle variations was proposed by Jelev et $\mathrm{al}^{2}$ and is indicated in -Fig. 1.

received

September 5, 2018

accepted

March 28, 2019
The unilateral and long type is the most frequent one, usually originating from the sternocleiomastoid (ECOM) muscle tendon and inserted into the costal cartilages. Silva ${ }^{3}$ reported a series of cases in cadavers presenting sternal muscle. In this study, these muscles had origins near the ECOM tendon or even at the manubrium.

In our study, the sternal muscle was dissected through the routine technique and is shown in - Fig. $\mathbf{2}$.

Our finding reveals a long, unilateral muscle with a length greater than the width and thickness, with proximal fixation in the sternal fascia of the pectoralis major muscle and the distal insertion in the abdominal portion of the pectoralis major muscle.

\section{Discussion}

The ontogenesis of the sternal muscle has revealed a muscle as being a reminiscent of four major structures: from the major spinal muscle; from the rectus abdominis muscle; from the musculoskeletal muscle, or from the fleshy panniculus related to the platysma muscle. ${ }^{4}$

Our finding reveals a long, unilateral muscle with a length greater than the width and thickness, with proximal fixation in the sternal fascia of the pectoralis major muscle and the

Copyright $\odot 2019$ by Thieme Revinter Publicações Ltda, Rio de Janeiro, Brazil

\section{License terms} 10.1055/s-0039-1688910. ISSN 2177-0298. 

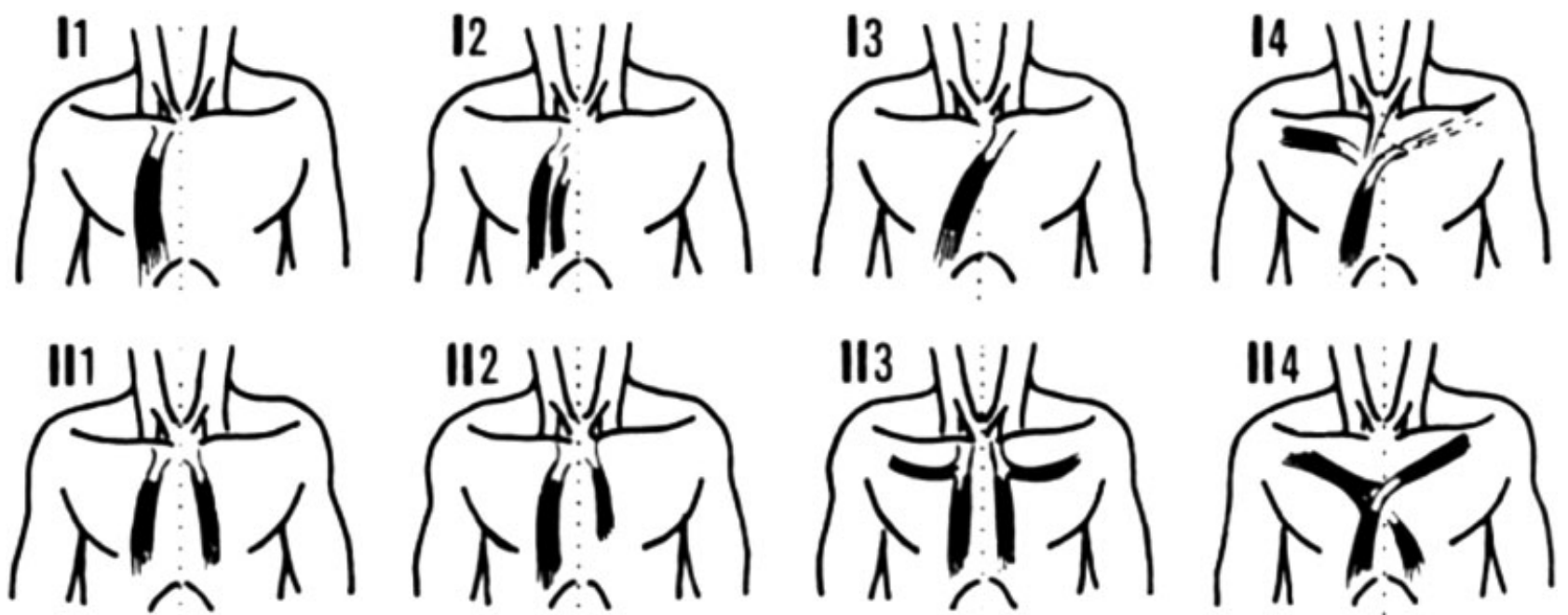

Fig. 1 Variant forms of the sternal muscle previously published by Jelev et al. ${ }^{2}$
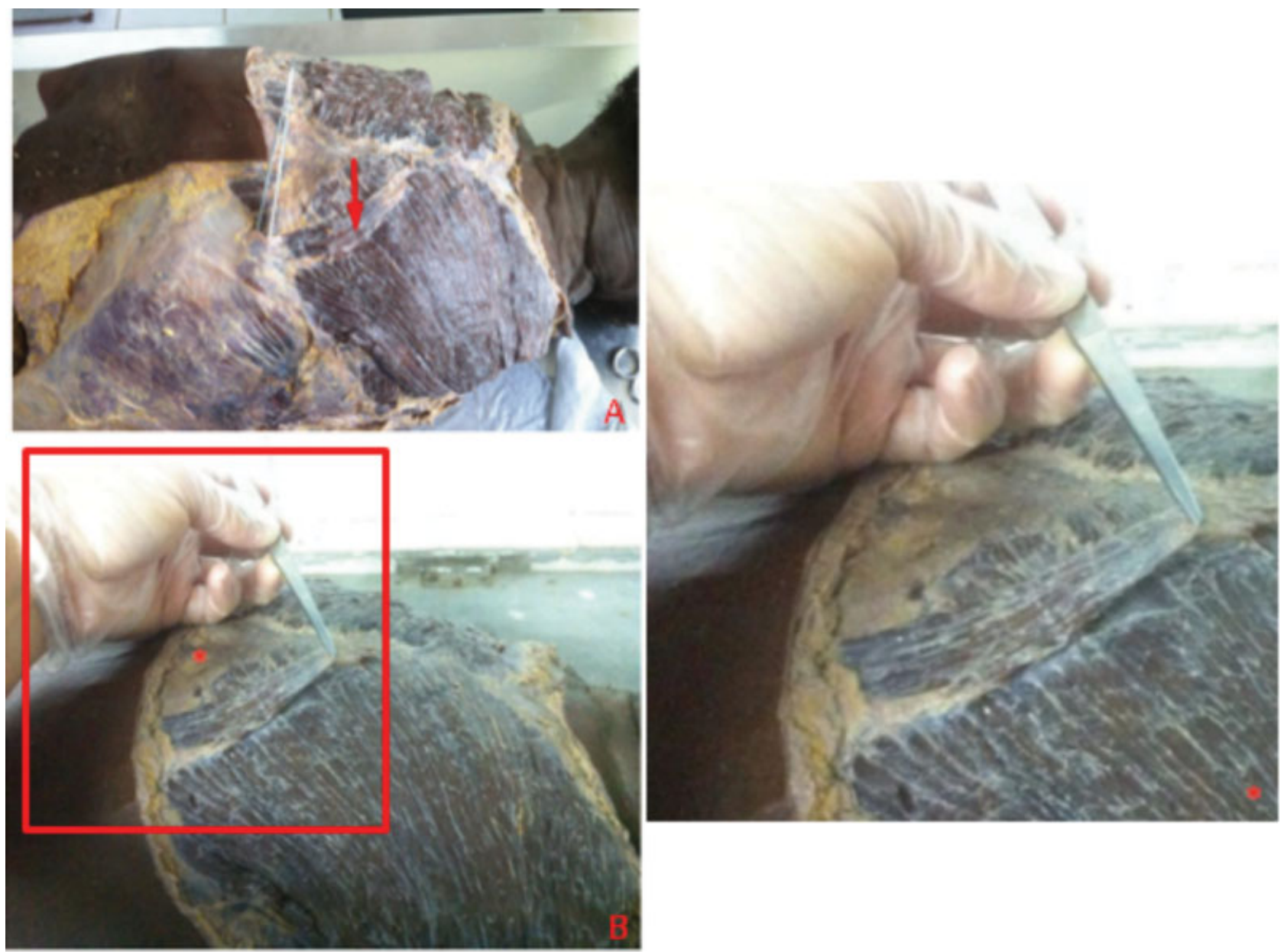

Fig. 2 Sternum muscle dissection, anterior to the pectoralis major muscle (A and B). Long muscle with parallel fibers $\left({ }^{*}\right)$.

distal insertion in the abdominal portion of the pectoral muscle. In the classification proposed by Jelev et $\mathrm{al}^{2}{ }^{2}$ our finding closely resembles type $\mathrm{I} 2$, with proximal fixation in the middle axial line of the sternum, but differs in presenting only one venter. Recently, Dudgeon et $\mathrm{al}^{5}$ also proposed a new variant form to the sternal muscle. This finding was a mixed type with three venters. Therefore, we believe that our finding can also be added to this classification. Interestingly, the phylogenetic theories state that the sternal muscle, when found near the sternum, is derived from primates. ${ }^{6}$

The visualization of the sternal muscle has caused surprise during surgeries. ${ }^{7}$ During radical mastectomies in the 
treatment of breast carcinomas, the pectoral fascia is folded and the pectoralis major is exposed. In the presence of the sternal muscle, it is necessary to observe its muscular fixations to perform the best cutting plane. ${ }^{1}$ In studies using mammography, the sternal muscle was identified, whereas at clinic evaluations it was confused with a mammary lesion. ${ }^{8}$

Therefore, documentation of sternal muscle variations can improve the anatomy theoretical database, as well as aid diagnoses, reducing the probability of the unexpected during clinical and/or surgical thorax-related investigations.

\section{Conflicts of Interests}

The authors have no conflicts of interests to declare.

\section{References}

1 Povedaa CA, Muñozc EJ, Camargo DC. Músculo esternalis: variante anatómica que simula neoplasia en mamografia. Rev Colomb Cancerol 2013;17(01):46-49
2 Jelev L, Georgiev G, Surchev L. The sternalis muscle in the Bulgarian population: classification of sternales. J Anat 2001; 199(Pt 3):359-363

3 Silva RG. Variação anatômica do músculo esternal: anatomia clínica e revisão da literatura. Salvador: Faculdade de Medicina da Bahia; Universidade Federal da Bahia; 2013:47 (Course conclusion monograph)

4 Raju S, Ragu J, Sreenivasulu RM, Sirisha B, Indira B, Sujata M. Na Unilateral Rectus Sternalis Muscle: It's Clinical Significance. Journal of Surgical Academia 2012;2(01):21-22

5 Dudgeon SN, Marcotte KM, Fox GM, Alsup BK. a previously unclassified variant of sternalis muscle. Surg Radiol Anat 2017: $1-3$

6 Bonfiglio NS, Kremer R, Anklam AP, Rios TJ, Guedert DG, Amorim MAP, Lima P. Incidência do músculo esternal em cadáveres dissecados entre os anos de 1989 e 2014 no laboratório de anatomia dafundação universidade regional de Blumenau. FURB.REVISTA SAÚDE E CIÊNCIA online 2015;4(03):98-105

7 Loukas M, Bowers M, Hullett J. Sternalis muscle: a mystery still. Folia Morphol (Warsz) 2004;63(02):147-149

8 Marques EF, Souza JA, Graziano L, Bitencourt AG, Senaga C, Fontes CE. [Sternalis muscle simulating a breast nodule]. Rev Bras Ginecol Obstet 2009;31(10):492-495 